\title{
Analysis of errors in derivatives of trigonometric functions
}

Sibawu Witness Siyepu

\begin{abstract}
Background: This article reports on an analysis of errors that were displayed by students who studied mathematics in Chemical Engineering in derivatives of mostly trigonometric functions. The poor performance of these students triggered this study. The researcher (lecturer) works in a mathematics support programme to enhance students' understanding of mathematics. The purpose of this study was to identify errors and their origins when students did calculations in derivatives of trigonometric functions. The participants of this study were a group of thirty students who were registered for Mathematics in a university of technology in Western Cape, South Africa. The researcher used a qualitative case study approach and collected data from students' written work. This study used Dubinsky's (1991) APOS Theory (Actions, Processes, Objects, and Schemas) to classify errors into categories and analyse the data collected.
\end{abstract}

Results: Errors displayed by students were conceptual and procedural; there were also errors of interpretation and linear extrapolation. Conceptual errors showed a failure to grasp the concepts in a problem and a failure to appreciate the relationships in a problem. Procedural errors occurred when students failed to carry out manipulations or algorithms, even if concepts were understood. Interpretation errors occurred when students wrongly interpreted a concept due to over-generalisation of the existing schema. Linear extrapolation errors occurred when students over-generalised the property $f(a+b)=f(a)+f(b)$, which applies only when $f$ is a linear function, to the form $f\left(a^{*} b\right)=f(a) * f(b)$, where $f$ is any function and * any operation. The findings revealed that the participants were not familiar with basic operational signs such as addition, subtraction, multiplication and division of trigonometric functions. The participants demonstrated poor ability to simplify once they had completed differentiation.

Conclusions: This study recommends the strategy of focusing on elimination of errors to develop students' understanding of derivatives of trigonometric functions. This can be done through learning activities that lead to identification and analyses of students' errors in classroom discussions.

Keywords: APOS Theory; Derivatives; Errors; Trigonometric functions

\section{Introduction and background}

This paper is part of a doctoral study conducted to explore students' errors in derivatives of trigonometric functions. This was to enable the researcher to establish causes and origins of such errors to develop a means of eliminating displayed errors. The poor performance of South African students in mathematics at secondary school and university is a major concern of various stakeholders (Makgato, 2007). There are several factors that are linked to the causes of such poor performance. Several

\footnotetext{
Correspondence: siyepus@cput.ac.za
}

Fundani Centre for Higher Education and Training, Cape Peninsula University of Technology, cnr Keizergracht \& Tennant Str Zonnebloem 7925, Cape Town 8000, South Africa researchers have found that errors and misconceptions displayed by students in their attempts to solve mathematical problems contribute to perpetuate their poor performance in their learning of mathematics (Brodie, 2005, 2006 \& 2010; Davis, 1984; Drews, 2005; Foster, 2007; Hatano, 1996; Luneta \& Makonye, 2010; Nesher 1987; Olivier, 1989; Orton, 1983a; Orton, 1983b; Ryan \& Williams, 2000 and Smith, DiSessa, \& Rosehelle, 1993). The idea that students develop 'misconceptions' has been the basis of much of the empirical research on learning mathematics and science for the last 15 years (Smith et al., 1993). Smith et al. (1993) highlight that "misconceptions arise from

\section{包 Springer}

(c) 2015 Siyepu. Open Access This article is distributed under the terms of the Creative Commons Attribution 4.0 International License (http://creativecommons.org/licenses/by/4.0/), which permits unrestricted use, distribution, and reproduction in any medium, provided you give appropriate credit to the original author(s) and the source, provide a link to the Creative Commons license, and indicate if changes were made. 
students' prior learning, either in the classroom (especially for mathematics) or from their interaction with the physical and social world" (p.10). They further elaborate that misconceptions can be stable and widespread among students and such misconceptions can be strongly held and resistant to change (ibid, p. 11). Orton (1983a) asserts that students have problems in understanding the meaning of the derivative when it is written as a fraction. His findings include different types of errors displayed by students in a calculus classroom.

This study focuses on errors displayed by students in derivatives of trigonometric functions. In this study, students who registered for tertiary mathematics had studied trigonometry towards the end of secondary school. Despite this, trigonometry remains a problem for students throughout their study of mathematics. Challenger (2009) asserts that students claim that trigonometry is difficult and they 'hate' it. They see trigonometry as a complicated section of mathematics and are confused as to whether they should apply triangle trigonometry, circle trigonometry and/or analytic trigonometry.

In South Africa, derivatives of trigonometric functions are introduced to the students for the first time in their first year in a university. In the secondary school curriculum, they studied derivatives of algebraic functions only. In their first year at university, they advance in their learning of mathematics through their study of derivatives of exponential, logarithmic and trigonometric functions in mathematics. Based on the reviewed literature, no studies have been conducted on errors in derivatives of trigonometric functions. Siyepu (2013a) presented a paper at a national conference of the Association for Mathematics Education of South Africa (AMESA) on students' interpretations in learning derivatives in a university mathematics classroom. The focus of that paper was an investigation of students' interpretations in their learning of derivatives owing to errors and misconceptions they displayed in their solutions (Siyepu, 2013a, p. 184). This study builds on the work of that paper as the author analyses errors displayed and explores causes and origins of errors in derivatives of trigonometric functions. Siyepu (2013b) explored students' errors in derivatives of various functions such as algebraic, exponential, logarithmic and trigonometric functions. Although this study (Siyepu, 2013b) investigated errors in derivatives of various functions, including trigonometric functions, there was no focus on derivatives of trigonometric functions. As a result, there was no depth in the analysis of data based on trigonometric functions. Jojo (2014) explores learners' understanding of the concept of chain rule in the learning of calculus. Her focus is on strategies to be used to develop relational understanding of the chain rule among students, not on errors displayed. Weber (2008) highlights that "despite the importance of trigonometry and students' potential difficulties in learning it, relatively little research has focused on this subject" (p.144).

The identification of errors might assist lecturers and mathematics teachers to focus on the development of pedagogical techniques that may overcome students' difficulties in their learning of derivatives of trigonometric functions. Brodie and Berger (2010) claim that "the notion 'misconception' empowers lecturers, since it provides them with a way to make sense of pervasive and persistent student errors without blaming students and themselves" (p.170). They argue that this is particularly the case where well-known misconceptions have been identified in certain topics of mathematics (Brodie \& Berger, 2010). Swan (2001) argues that if lecturers become more aware of common errors, they will be in a better position to help students to restructure their knowledge in the direction of more aligned mathematical knowledge.

The essence of the study was to explore errors displayed by students in their learning of derivatives of trigonometric functions and to make some recommendations that might enhance students' learning of this subject. To be explicit, this study sought to answer the following questions:

- What kinds of errors are displayed by first year university students in their learning of derivatives of trigonometric functions?

- What are the tentative origins or causes of the errors displayed by the students in their solutions of derivatives of trigonometric functions?

\section{Errors in trigonometry}

Trigonometry, as a branch of mathematics that deals with the relationships of sides and angles in triangles, forms an important background for the solution of problems in many disciplines (Orhun, 2010). Trigonometry is frequently used in mathematical explanations and definitions of new ideas and concepts. For example, trigonometric ratios are used to describe the relationship of angles and sides in a right-angled triangle. Research studies reveal that many students have not developed clear concepts in trigonometry and that some of them use algebraic notation informally (Maharaj, 2008).

Orhun (2010) states that students registered for calculus in their first year at a university perform badly in the operations of trigonometric expressions, namely addition, subtraction, multiplication and division. For example, students demonstrate difficulties in the multiplication of $\sin$ $x \times \sin x$. Orhun (2010) argues that this may be due to the fact that there may not be much emphasis in the learning of addition, subtraction, multiplication and division of trigonometric functions in the secondary school curriculum. This is evident from Table 1 which shows trigonometry recommended in the 2011 South African curriculum of the Department of Basic (DoBE). In addition, many 
Table 1 Trigonometry in high school curriculum in South Africa

\begin{tabular}{|c|c|c|}
\hline Grade 10 & Grade 11 & Grade 12 \\
\hline $\begin{array}{l}\text { (a) Definitions of the trigonometric ratios } \sin \theta, \\
\cos \theta \text { and } \tan \theta \text { in right-angled triangles. }\end{array}$ & $\begin{array}{l}\text { (a) Derive and use the identities: } \\
\sin \theta \tan \theta=\cos \theta \sin ^{2} \theta+\cos ^{2} \theta=1 \text {. }\end{array}$ & \multirow{4}{*}{$\begin{array}{l}\text { Proof and use of the } \\
\text { compound angle and double } \\
\text { angle identities. }\end{array}$} \\
\hline $\begin{array}{l}\text { (b) Extend the definitions of } \sin \theta, \cos \theta \text { and } \\
\tan \theta \text { to } 0^{\circ} \leq \theta \leq 360^{\circ} \text {. }\end{array}$ & (b) Derive the reduction formulae. & \\
\hline $\begin{array}{l}\text { (c) Derive and use values of the trigonometric ratios (without } \\
\text { using a calculator for the special angles }\left\{\theta \in 0^{\circ} ; 30^{\circ} ; 45^{\circ} ; 60^{\circ} ; 90^{\circ}\right\} \text {. }\end{array}$ & $\begin{array}{l}\text { (c) Determine the general solution and/or } \\
\text { specific solutions of trigonometric equations. }\end{array}$ & \\
\hline (d) Define the reciprocals of trigonometric ratios. & (d) Establish the sine, cosine and area rules. & \\
\hline Solve problems in two dimensions. & Solve problems in two dimensions. & $\begin{array}{l}\text { Solve problems in two and } \\
\text { three dimensions. }\end{array}$ \\
\hline
\end{tabular}

students study the derivatives of trigonometric functions for the first time in their first year at a university. This implies they have not yet developed the schema of addition, subtraction, multiplication and division in derivatives of trigonometric functions. The weaknesses of students in these operations of trigonometric functions lead to poor manipulation of trigonometric functions when such students are faced with trigonometric problems that require further simplification. Table 1 shows what is recommended in the South African secondary school trigonometry curriculum (Department of Basic Education DoBE 2011).

Orhun (2010) suggests that:

In order for lecturers to account for students' systematic errors from a constructivist perspective, analysing the procedures is not sufficient, since lecturers should analyse students' current schemas and how they interact with each other according to instruction and experience. (p. 182)

Skane and Graeber (1993) claim that some errors displayed by students in the content of algebra, logarithms, exponents and trigonometry are attributed to the distributive law. They further suggest that traditional instruction is not a sufficient strategy to remediate distributive law errors for some students. This applies in compound angle formulae such as $\operatorname{Cos}(x+y)=\operatorname{Cos} x \operatorname{Cos} y-\operatorname{Sin} x \operatorname{Sin} y$. The use of distributive property in an algebraic expression familiarises students with $x(a+b)=a x+b x$.

Researchers such as Thompson et al. (2013) suggest the use of a conceptual approach to teach calculus as a better option compared to the traditional approach. The traditional approach commonly known as the procedural approach may be defined as lecturer-led with direct instruction of rules or procedures for solving problems (Peal, 2010). The opposite end of the instructional spectrum from the procedural approach is the conceptual approach. Conceptual-based instruction seeks to provide reasons why these algorithms and formulae work (Peal, 2010). In the conceptual approach, the emphasis is on the students' learning important concepts of mathematical connections, relationships and applications.
The rise of the conceptual approach in mathematics instruction is consistent with a constructivist approach to education (Peal, 2010).

\section{Students' difficulties in calculus}

The study of calculus, with its fundamental concepts of limit, derivative and integral, requires an ability to understand algebraic variables as generalised numbers and as functionally related varying quantities (Gray, Loud, \& Sokolowski, 2009). Students' performance in calculus is undermined by weak basic algebraic skills of factorisation, handling operations in directed numbers, solving equations and poor understanding of indices (Luneta \& Makonye, 2010). They further argue that algebraic incompetence has a direct impact on learning calculus. They suggest that lecturers should be aware of the educational backgrounds of first year university students in order to design learning activities that may close any gaps that exist between matriculation and the first year university level. Students often misunderstand the notion of a function and the concept of a limit, which together, form the cornerstone of several related concepts such as continuity, differentiability, integration and convergence of sequences and series (Tarmizi, 2010).

\section{Students' understanding of first principles of differentiation}

The application of first principles of differentiation to learn derivatives of various functions is a significant component for developing the rules of differentiation among students who intend to study advanced mathematics. The first principles of differentiation are defined by the formula $f^{\prime}(x)=\lim _{h \rightarrow 0} \frac{f(x+h)-f(x)}{h}$.

This formula is used to develop standard rules of differentiation such as $\frac{d}{d x}(\sin x)=\cos x ; \frac{d}{d x}(\tan x)=\sec ^{2} x$; $\frac{d}{d x}(\cos x)=-\sin x$. The formula of first principles of differentiation is also used to develop standard derivatives of reciprocals of the three basic trigonometric functions mentioned above, namely, cosecant, cotangent and secant. Naidoo and Naidoo (2009) state that the derivative 
can be seen as a concept, which is built from other concepts. They further argue that the derivative can be seen as a function, a number if evaluated at a point, a limit of the sequence of secant slopes or a rate of change. Each advanced concept in mathematics is based on elementary concepts and cannot be grasped without a solid and specific understanding of the elementary concepts.

Ryan (1992) indicates that most students have a limited concept image for the gradient. Tall and Vinner (1981) define 'concept image' as all the cognitive structures in the individual's mind that are associated with a given concept. Understanding the concept image assists students to be able to apply rules related to the concept appropriately. For example, students tend to confuse rules of differentiation to be applied in the following functions $\left(y=x^{n} ; y=x^{x} ; y=a^{x}\right)$ when they have a limited concept image of each function.

Ryan (1992) recommends that the development of global ideas associated with the gradient of a straight line should be a focus of learning before the idea of gradient of a curve is introduced in beginner calculus. He further elaborates that some students indicate fundamental problems with slope as a rate of change.

According to Ryan (1992), the traditional first principles approach has been found to be cognitively demanding for students who demonstrate rote learning in their application of first principles of differentiation to find derivatives. He recommends that more time should be given to the notion of a tangent to a curve in the first principles approach to differentiation. The situation of memorising rules can foster instrumental understanding which may leave students without the relational understanding of what is required in order to make sense of mathematics learning (Skemp, 1976). Relational understanding does not involve only knowing what to do, but also why, as it includes rationalisation of the underlying mathematical relationship and properties (Choat, 1981). Instrumental understanding occurs when students think that they understand something if they are able to obtain correct answers to a given category of questions without knowing why the method works (Choat, 1981, p.18). For instance, in a situation that involves the following $\left(y=x^{n}\right.$; $y=x^{x} ; y=a^{x}$ ), students tend to be confused where to apply a certain rule if they have an instrumental understanding of the rules such as power rule, logarithmic rule and exponential function rule.

Maharaj (2008) claims that "the teaching implication of identifying errors in the learning process is that before students are required to use and manipulate algebraic and trigonometric functions, the meanings of symbols must be established" (p. 402). The exploration of errors in learning derivatives of trigonometric functions is likely to promote an understanding of special limits and symbols that are involved in learning standard derivatives of trigonometric functions.

Brodie (2010) argues that "errors make sense when understood in relation to the current conceptual system of the student, which is usually a more limited version of a mature conceptual system" (p. 13). The implication of Brodie's (2010) argument is that lecturers should consider their students' prior knowledge in order to assess what students know and thus be able to accommodate new knowledge. This can be done by allowing students to write baseline assessment tasks. Analysis of baseline assessment tasks may assist lecturers to identify students' errors and their causes or origins. Correcting students' errors of current conceptual structures should help them to become more powerful through increasing their understanding in a range of situations (Brodie, 2010).

\section{Students' understanding of the concept "derivative"}

Pillay (2008), Siyepu (2013a) and Zandieh (1997a; 1997b; 2000 ) suggest that the concept of a derivative can be represented in many ways. Siyepu (2013a) gives examples, namely, graphically, as the slope of a tangent line to the curve at a point; verbally, as the instantaneous rate of change; physically, as speed or velocity and symbolically, as the limit of the difference quotient. The current study focused on the symbolic representation of the derivative that is based on an expression for the average gradient, which is written as $f^{\prime}(x)=\lim _{h \rightarrow 0} \frac{f(x+h)-f(x)}{h}$. This study used this formula to develop understanding of standard derivatives of trigonometric functions. The study also introduced the derivative as a rate of change with students having to show an understanding of using the first principles of differentiation to find standard derivatives. The derivative as the rate of change uses the Leibniz's notation. In Leibniz's notation for differentiation, the derivative of the function $f(x)$ is written as $\frac{d(f(x))}{d x}$. If we have a variable representing a function, for example, if we set $y=f(x)$, then we can write the derivative as $\frac{d y}{d x}$.

The findings of Ubuz (2001) in her research on first year engineering students' understanding of tangency, numerical calculation of gradients and the approximate value of a function at a point through computers reveal that students have the following misconceptions about the derivative:

- The derivative at a point gives the function at a point.

- The tangent equation is the derivative function.

- The derivative at a point is the tangent equation.

- The derivative at a point is the value of the tangent equation at that point. 
The exploration of errors may assist students to address these types of misconceptions as students and lecturers interact in their classroom discussions.

Calculus requires a high level of conceptual understanding, yet many students struggle to make sense of differentiation (Paramenswaran 2007; Siyepu, 2013a). Some students show an inadequate understanding of the concepts of function and variable (Barnes, 1995; Siyepu, 2013a). Barnes (1995) also claims that there is a lack of awareness that a derivative is a rate of change. Uygur and Ozdas (2005) and Siyepu (2013a) assert that the derivative is a difficult concept for many students. They further explain that it is worse when the function considered is a composite function. Tall (1993) indicates that "the Leibniz notation $\frac{d y}{d x}$ proves to be almost indispensable in the calculus" (p.19). Yet, it causes serious conceptual problems with students whether it represents a fraction or a single individual symbol (Tall, 1993, p. 19). He further explains that one difficulty with the notion of the chain rule is the dilemma of whether the $d u$ can be cancelled in the equation $\frac{d y}{d x}=\frac{d y}{d u} \times \frac{d u}{d x}$. The interpretation of chain rule does not allow students to cancel; instead, they are expected to find the derivative with respect to $u$ first and find the derivative with respect to $x$.

\section{Students' understanding of rules of differentiation}

Studies of students' difficulties with calculus topics may offer insights into understanding misconceptions and errors which are committed by students when doing calculus (Clark et al., (1997); Siyepu, 2013a). Mundy (1984) asserts that there is "a tendency of calculus students to operate at a rote level of procedures and symbol manipulation, which is not supported by an understanding of the concepts involved" (p.171). As a result, students fail to use calculus strategies when dealing with nonroutine problems (Clark et al., 1997). Barnes (1995) suggests that "students should not be taught rules for differentiation until they have developed a good understanding of what a derivative is, and a familiarity with the relationship between a function and its derivative" (p. 4). She further elaborates that students should explore techniques on how to find and investigate derivatives of a variety of different functions.

Barnes (1995) emphasises that this may help to avoid what Ryan (1992) has described as "the rush to the rule", where the meaning is ignored or forgotten, and students operate on a purely mechanical level, pushing symbols around on paper. This suggests that teaching should focus on making sense of mathematical symbols, signs and formulae (Siyepu \& Ralarala, 2014).

The chain rule is a calculus concept that causes difficulties for many students (Jojo, 2014; Siyepu, 2013a; Wangberg, Engelke \& Karakok, 2010). The derivatives of trigonometric functions become complicated when they need the application of the chain rule. Literature also shows that function composition is particularly problematic for students (Engelke et al., 2005; Siyepu, 2013a). Some students are introduced to the chain rule merely as a rule that should be applied without much attempt to reveal the reasons for and justification of the procedure (Orton, 1983b; Siyepu, 2013a). The chain rule concept, as an example of a schema, requires that students should already be at a well-functioning schema level for all other standard basic rules of differentiation (Clark et al., 1997; Siyepu, 2013a). This suggests that the concept of the chain rule should be introduced only when students can operate automatically with other rules of differentiation such as the multiple constant rule, the sum and the difference rule, the power rule, the product rule and the quotient rule. According to APOS Theory, prior to the introduction of chain rule, the students should be at a schema level for the rules mentioned above. Due to time limitations, lecturers proceed to a section of the chain rule without clear evidence that students can perform independently in other prerequisite sections, such as those mentioned above.

The literature related to studies in calculus provides evidence that students develop more procedural than conceptual understanding in differentiation with regard to the application of the chain rule (Wangberg et al., 2010). Some students fail to recognise that differentiating functions such as $y=\cos \pi x$ requires the use of the chain rule (Wangberg et al., 2010).

Jojo et al. (2011) claim that "the complexity of the chain rule deserves exploration because students struggle to understand it and because of its importance in the calculus curriculum" (p. 337). The current study explores derivatives of trigonometric functions involving all the rules of differentiation. Uygur and Ozdas (2005) state that many students are able to evaluate the derivative of special composite functions by memorised rules, but most of them calculate these derivatives without the conscious use of the chain rule.

They further argue that although many students provide a general statement of the chain rule and write down the formula, only a few of them can explain the connection between the statement and memorised rules. They suggest that, in teaching the concept of the chain rule, more emphasis should be given to using the Leibniz notation meaningfully, to relate both special cases and abstract cases to the general statement of the chain rule in order to avoid such misconceptions. Uygur and Ozdas (2005) further suggest that another important point when teaching the chain rule is to prompt students by relating the composition function notions to various functions, especially abstract problem situations, which embody the chain rule concept. 


\section{Theoretical framework}

This section discusses APOS Theory as the theoretical framework underpinning this study. It discusses stages of APOS Theory, genetic decomposition and genetic decomposition for derivatives of trigonometric functions.

This study is underpinned by Dubinsky (1991) APOS Theory. The acronym APOS stands for Action, Process, Object and Schema. Arnon et al. (2014) state that "APOS is a theory of how mathematical concepts can be learned" (p.1).

Arnon et al. (2014) explain that:

APOS Theory focuses on models of what might be going on in the mind of an individual when he or she is trying to learn a mathematical concept and uses these models to design instructional materials and/or to evaluate student successes and failures in dealing with mathematical problem situations. (p.1)

This study focuses on errors displayed by students in derivatives of trigonometric functions. The stages of APOS Theory were used to analyse the data collected.

\section{Stages of APOS Theory}

An action stage of the APOS Theory is where each step of the learning process (transformation) needs to be performed clearly and guided by external instructions (Arnon et al., 2014, p. 4). Action is based on rules and algorithms, where a rule is practised repeatedly until it becomes routine; and this takes place without adequate thinking (Brijlall \& Ndlovu, 2013). In the case of trigonometric functions, an individual needs to know the concept of a function first and be able to distinguish trigonometric functions from other functions, such as algebraic, exponential and logarithmic functions. At the same time, students need to know the unique characteristics of trigonometric functions.

The process stage of the APOS Theory is where actions are repeated and reflected upon, the individual moves from relying on external clues to having internal control over them (Arnon et al., 2014, p. 4). This stage is characterised by an ability to imagine carrying out the steps, without necessarily having to perform each one explicitly, and being able to skip steps, as well as reverse them. In derivatives of trigonometric functions, an individual should know derivatives of basic trigonometric functions without using the first principles of differentiation to prove them.

An object is constructed from a process when the individual becomes aware of the process as a totality and realises that transformations can act on it (Dubinsky \& McDonald, 2001).

Finally, a schema for a certain mathematical concept is an individual's collection of actions, processes, objects and other schemas which are linked by some general principles to form a framework in the individual's mind so that may be brought to bear upon a problem situation involving that concept. For example, in the case of derivatives of trigonometric functions, an individual can apply all the rules of differentiation to find the derivatives of the given function (Dubinsky \& McDonald, 2001).

\section{Genetic decomposition}

A genetic decomposition is a proposed standard that describes the typical structures and devices that a student might need to construct in order to learn a specific mathematical concept (Arnon et al., 2014). Arnon et al. (2014) noted that genetic decomposition starts as a proposition based on the researchers' experiences in the learning and teaching of the concept, their knowledge of APOS Theory. The understanding of any mathematical concept depends on prior knowledge of what students have encountered before. This prerequisite knowledge lays a foundation for the new mathematical concept to be studied, thus linking the new knowledge with existing knowledge.

\section{Genetic decomposition for derivatives of trigonometric functions}

Students should explore basic knowledge of derivatives, starting from algebraic, exponential, logarithmic and later trigonometric functions. Students who are registered for Mathematics in their first year might not understand derivatives of trigonometric functions if they are not at an adequate schema level in their differentiation of other various functions. For students to grasp derivatives of trigonometric functions, they should be able to distinguish laws, rules and notations based on derivatives of different functions. They should be able to see relationships in various functions and be able to build logic in various schemas of the key derivatives of various functions. For instance, students should be able to recognise a situation where they have to apply different rules of differentiation in a mathematical problem. As this was a doctoral study, the author piloted a genetic decomposition schema of trigonometric functions. For more details, see Siyepu (2013b).

\section{Research methods}

This study is located within the interpretative qualitative research paradigm. Qualitative research is an exploratory approach, which emphasises the use of open-ended questions and probes, giving participants an opportunity to respond in their own words (Devetak et al., 2010).

\section{Research participants}

The research participants of the study were the thirty students who were registered for Chemical Engineering in an extended curriculum programme (ECP). The curriculum is designed for students who are "borderline" cases (Siyepu, 2013b). These students do not meet the 
minimum academic requirements for admission to the main engineering stream but, based on psychometric testing, show potential to succeed in their studies (Siyepu, 2013b). In an ECP, students study the same content of mathematics as other students in the main engineering stream, but instead of completing it within a semester, they have to do it over a year (Siyepu, 2013b). The way this is done is to add active learning components to the curriculum such as group work, projects, peer work as well as other related support work, such as how to read the subject texts, how to solve problems and how to represent knowledge in the field (Siyepu, 2010, 241-242). One of the researcher's job descriptions is to assist students who are at risk to improve their performance in the learning of mathematics (Siyepu, 2013b).

The sample group in the study had the following characteristics:

- They were all full time students.

- They all used English as an additional language.

- They were thirty students who enrolled for Chemical Engineering in 2009.

- There were (16 female and 14 male) students.

- Twenty-two of the students had matriculated in 2008.

- Seven students had matriculated in 2007.

- One student had matriculated in 2006.

- Twenty-nine students had matriculated in mathematics in South African schools.

- One was an international student with a qualification equivalent to South African matriculation.

- Their ages ranged from 18 to 21 years, with one student of 25 years.

\section{Data collection}

For this study, the researcher adopted an APOS investigation cycle from Dubinsky and McDonald (2001). An APOS investigation cycle was designed to develop theoretical design, implementation and analysis of instruction and to guide collection and analysis of the data.

The investigation cycle went through the steps, as shown in Fig. 1.
This study used an APOS pedagogical approach known as the ACE teaching cycle which consists of activities, classroom discussions and exercises to collect data.

\section{Activities}

Students were administered formative assessments in the form of written tasks to collect data.

\section{Classroom discussions}

Students, together with the lecturer, gathered in a lecture room to discuss, argue and justify their solutions in the form of a revision task. This created an open discussion forum as a space in which students question one another to clarify reasons for choices, while sharing information to reach consensus about the correct solution to a mathematical problem. In discussion forum, the lecturer, as researcher in this study, was able to identify students' errors as they discussed their interpretation of the mathematical concepts under study.

\section{Exercises}

Exercises were given to students to reinforce their understanding once corrections of the displayed errors in their written tasks and classroom discussions were done. Mathematical problems were designed as exercises intended to focus on the elimination of the errors displayed to enhance students' understanding of the topic under study. The following three figures show the tests given to the students with Fig. 2 showing the first of these tests.

The second test administered consisted of three main questions with two sub-questions in Question 1 and three sub-questions in Questions 2 and 3. This is shown in Fig. 3.

The third test was administered to students to test their understanding of derivatives of trigonometric functions in their application of the quotient rule and logarithmic differentiation. The test comprised three questions. This is shown in Fig. 4.

\section{Data analysis}

The APOS Theory is used as a language for communication of ideas about learning. In this study, analysis was carried out by examining students' responses for each item. Students' scripts were marked and grouped

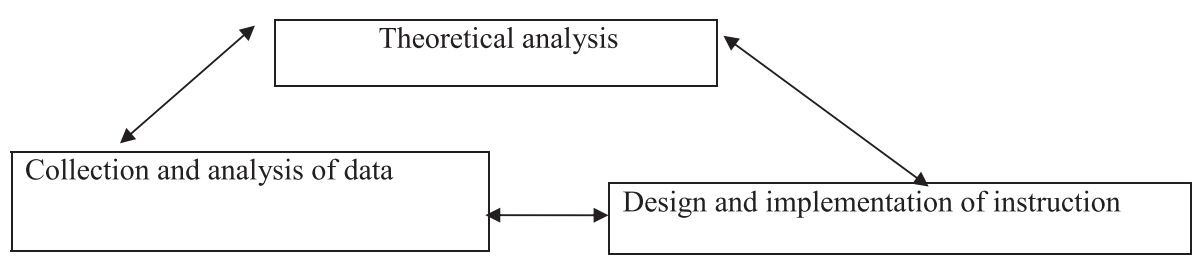

Fig. 1 Investigation cycle used in APOS Theory 
Use the first principles of differentiation to find the derivative of the function below:

$f(x)=\cos x$

Fig. 2 The first test given to the students in the study

according to common errors. This study identified errors as discussed below:

- Conceptual errors, according to Kiat (2005), show a failure to grasp the concepts in a problem and a failure to appreciate the relationships in a problem.

- Interpretation errors, according to Olivier (1989), occur when students wrongly interpret a concept due to over-generalisation of the already existing schema.

- Linear extrapolation errors occur when students over-generalise the property $f(a+b)=f(a)+f(b)$, which applies only when $f$ is a linear function, to the form $f\left(a^{*} b\right)=f(a) * f(b)$, where $f$ is any function and * any operation (Matz, 1980).
- Procedural errors, according to Kiat (2005), occur when students fail to carry out manipulations or algorithms, even if concepts are understood.

The data analysis paid attention to the errors displayed by students in their calculations, and the researcher (lecturer) worked out tentative causes or origins of the errors displayed in calculations. I adapted Maharaj (2013) to develop a table of examples of what student work represents, namely, an action conception, a process conception, an object conception and a well-functioning schema. Table 2 shows the kinds of student work that represents an action conception, a process conception, an object conception and a well-functioning schema in derivatives of trigonometric functions.

$$
\begin{aligned}
& \text { Find the derivatives of the following functions and leave your answer in the simplest } \\
& \text { form. } \\
& 1.1 y=3 x^{4}-\tan x \csc x \\
& 1.2 \quad y=4 x^{3 / 2} \sin x \\
& \text { Prove the following rules of differentiation } \\
& 2 \frac{d(\sec x)}{d x}=\sec x \tan x \\
& 2.1 \frac{d(\cot x)}{d x}=-\csc x^{2} \\
& 2.3 \frac{d(\csc x)}{d x}=-\csc x \cot x \\
& \text { Find the derivatives of the following functions and leave your answer in the simplest } \\
& \text { form. } \\
& 3.1 y=\sec \left(x^{4}\right) \cot { }^{3}\left(x^{4}\right) \\
& 3.2 y=\sqrt{\sin ^{4}(7 x)+\ln (5 x)} \\
& 3.3 \sqrt{\cot 7 x}
\end{aligned}
$$

Fig. 3 The second test given to the students in the study 


Find the derivatives of the following functions and leave your answer in the simplest
form.
$1.1 y=\frac{\sec \theta}{1-\csc \theta}$
$1.2 y=x^{3} e^{2 x+3} \sqrt{\cos x}$
$1.3 y=\sec ^{2} x e^{-\tan ^{2} x}$

Fig. 4 The third test given to the students in the study

\section{Results from the study}

The discussion here covers different kinds of errors displayed by student participants in their calculations of three tasks administered to them. The first assessment task was to use the first principles of differentiation to find the derivative of $y=\cos x$.

\section{Conceptual errors displayed by students in task 1}

This section presents conceptual errors displayed by students in task 1 . For example, one student out of $30 \mathrm{did}$ not manipulate $\quad \lim _{h \rightarrow 0} \frac{-\sin x \sinh }{h}=-\sin x \lim _{h \rightarrow 0} \frac{\sinh }{h}=-\sin x \cdot 1=-$ $\sin x$. She showed a problem in her understanding of special limits. Two students wrote incorrect compound angle formulae. For example, they wrote $\cos (A+B)=$ $\cos A \cos B+\sin A \sin B$ instead of $\cos (A+B)=\cos A$ $\cos B-\sin A \sin B$. The error, in this instance, was to write a plus sign instead of a minus sign between cos $A \cos B$ and $\sin A \sin B$.
Linear extrapolation errors displayed by students in task 1

This section presents linear extrapolation errors displayed by a student in task 1 . One student out of 30 multiplied in $\lim _{h \rightarrow 0} \frac{\cos (x+h)-\cos (x)}{h}$ to obtain $\lim _{h \rightarrow 0} \frac{\cos x+\cosh -\cos (x)}{h}$. This reveals poor understanding of the cosine compound angle formula. This student did not register in his mind that the correct formula for a cosine compound angle is $\cos (x+h)=\cos x$ $\cosh -\sin x \cos x$. This student is not even at an action stage of the APOS Theory regarding the cosine compound angle formula. This might be caused by little emphasis or no teaching of the compound angle formula at secondary school level. Table 3 shows errors displayed by students in task 1 .

\section{Conceptual errors displayed by students in task 2}

Two students did not know that the derivatives of $y=$ $\tan x$ is $\frac{d y}{d x}=\sec ^{2} x$. They wrote $-\sec ^{2} x$ and $\sec x \tan x$ as the derivative of $y=\tan x$. These students cannot recall

Table 2 This shows examples of what work represents stages of APOS Theory

\begin{tabular}{|c|c|c|}
\hline APOS stages & Description of each stage of APOS Theory & $\begin{array}{l}\text { Kind of student work that represents } \\
\text { each stage of APOS Theory }\end{array}$ \\
\hline Pre-action stage & $\begin{array}{l}\text { This is when a student is not yet at an action stage, } \\
\text { where he/she is still underdeveloped to learn a concept. }\end{array}$ & $\begin{array}{l}\text { For example, a student who cannot recall the } \\
\text { derivative of } \tan x \text {. }\end{array}$ \\
\hline Action stage & $\begin{array}{l}\text { A transformation is first conceived as an action, when it } \\
\text { is a reaction to stimuli which an individual perceives as } \\
\text { external. For example, a student who requires an explicit } \\
\text { expression to think about the derivative of a function. }\end{array}$ & $\begin{array}{l}\text { For example, to find the derivative of } f(x)=\sin x \text {, } \\
\text { a student who can do little more than perform the } \\
\text { action } f^{\prime}(x)=\cos x \text { is considered to have an action } \\
\text { understanding of the derivative of a function. }\end{array}$ \\
\hline Process stage & $\begin{array}{l}\text { A process is a mental structure that performs the same } \\
\text { operation as the action but wholly in the mind of the } \\
\text { individual. Specifically, a student can imagine performing } \\
\text { transformation without executing each step explicitly. }\end{array}$ & $\begin{array}{l}\text { For example, a student can perform the derivative } \\
\text { of the function } f(x)=\cos ^{2} x \text { by rewriting this as } \\
f(x)=\cos x \cdot \cos x \text { and apply the product rule to find } \\
\text { the derivative. }\end{array}$ \\
\hline Object stage & $\begin{array}{l}\text { If one becomes aware of a process stage in totality,for } \\
\text { example, when a student can find the derivative of a } \\
\text { function by applying various actions and processes, then } \\
\text { we say she/he is at an object stage. This could be a } \\
\text { student being able to see a function as the composite of } \\
\text { two functions. }\end{array}$ & $\begin{array}{l}\text { For example, to find the derivative of } f(x)=\tan ^{2} x^{2} \\
\text { requires application of a chain rule by applying the } \\
\text { power rule first and the derivative of a tangent function } \\
\text { and then lastly, the derivative of } x^{2} \text {; the answer is } \\
f^{\prime}(x)=2 \tan x^{2} \cdot \sec ^{2} x^{2} \cdot 2 x \\
\Rightarrow f^{\prime}(x)=4 x \tan x^{2} \sec ^{2} x^{2} \text {. }\end{array}$ \\
\hline Schema stage & $\begin{array}{l}\text { If one is able to apply various actions, processes and objects } \\
\text { that need to be organised and linked as a coherent framework. }\end{array}$ & $\begin{array}{l}\text { For example, to find the derivative of } \\
\qquad y=x^{3} e^{2 x+3} \sqrt{\cos x}\end{array}$ \\
\hline
\end{tabular}


Table 3 Frequency table of students' errors in task 1

\begin{tabular}{lllll}
\hline $\begin{array}{l}\text { Students' written } \\
\text { work in task1 }\end{array}$ & $\begin{array}{l}\text { No. of linear } \\
\text { extrapolation } \\
\text { errors }\end{array}$ & $\begin{array}{l}\text { No. of conceptual } \\
\text { errors }\end{array}$ & $\begin{array}{l}\text { No } \\
\text { errors }\end{array}$ \\
\hline Question & 1 & 1 & 3 & 26 \\
\hline
\end{tabular}

the derivative of a tangent function. They are at the preaction stage of the APOS Theory. The pre-action stage is where students are not yet ready to study a certain concept. This is evident by a situation where a student cannot start even the first step of a problem correctly. These students need repetition, or step-by-step instruction, to be able to remember the derivative of a tangent function. One student converted $\sec x$ into $\frac{1}{\sin x}$. Another one used incorrect identities as she wrote $\cot x=\frac{\sin x}{\cos x}$ and $\csc x=\frac{1}{\cos x}$, which were incorrect as the correct identities are $\cot x=\frac{\cos x}{\sin x}$ and $\csc x=\frac{1}{\sin x}$, respectively. Their attempts to find the derivative of a tangent function demonstrate that they entered first year university not yet ready to grasp derivatives of trigonometric functions. They probably do not even know what to do when they are instructed to find the derivative of a trigonometric function as they opt for using reciprocals and identities. Eight students did not apply trigonometric identities in simplification of trigonometric functions, as shown in Fig. 5.

\section{Interpretation errors displayed by students in task 2}

One student demonstrated a poor understanding of the constant multiple rule in his differentiation of $y=3 x^{4}$.
Instead, he applied a product rule. The product rule is correct when followed accurately, but this method is laborious and superfluous; hence, the more economical rule is the constant multiple rule.

Four students treated $y=4 x^{3 / 2}$ as if is a composite function, which it is not. They applied the constant multiple rule and the power rule to obtain $\frac{d y}{d x}=6 x^{1 / 2}$, and then they differentiated $y=4 x$ again to obtain $\frac{d y}{d x}=4$. This error originates from an over-generalisation of the differentiation of a composite function of trigonometric functions, which applies only to trigonometric functions and not to algebraic terms such as $4 x$. These students might be located at an action stage of APOS Theory regarding composite functions. One student wrote $6 x^{1 / 2}$ as equal to $\sqrt{6 x}$ and obtained $y=\sqrt{6 x} \cdot \sin x$, as is clear from Fig. 6, then they differentiated $y=\sqrt{6 x} \sin x$ as the original problem. This student did not understand that in $6 x^{1 / 2}$ the index $1 / 2$ affects $x$ only and $6 x^{1 / 2}$ can be written as $6 \sqrt{x}$ not as $\sqrt{6 x}$. This student might have a problem in understanding the distributive property of exponents. This reveals that poor conceptualisation leads to misinterpretations during the calculation processes. This originates from the fact that $\sqrt{x}$ can be written as $x^{1 / 2}$. This student fails to understand that in the case of $\sqrt{6 x}$, the number 6 is included in the square root. The following figure shows an example of the student who demonstrated an interpretation error in the differentiation of $y=4 x^{3} / 2 \sin x$.

One student differentiated $y=4 x^{3 / 2}$ to obtain $\frac{d y}{d x}=6 x^{1 / 2}$ and differentiated $y=x^{3 / 2}$ again to obtain $\frac{d y}{d x}=\frac{3}{2} x^{1 / 2}$. This

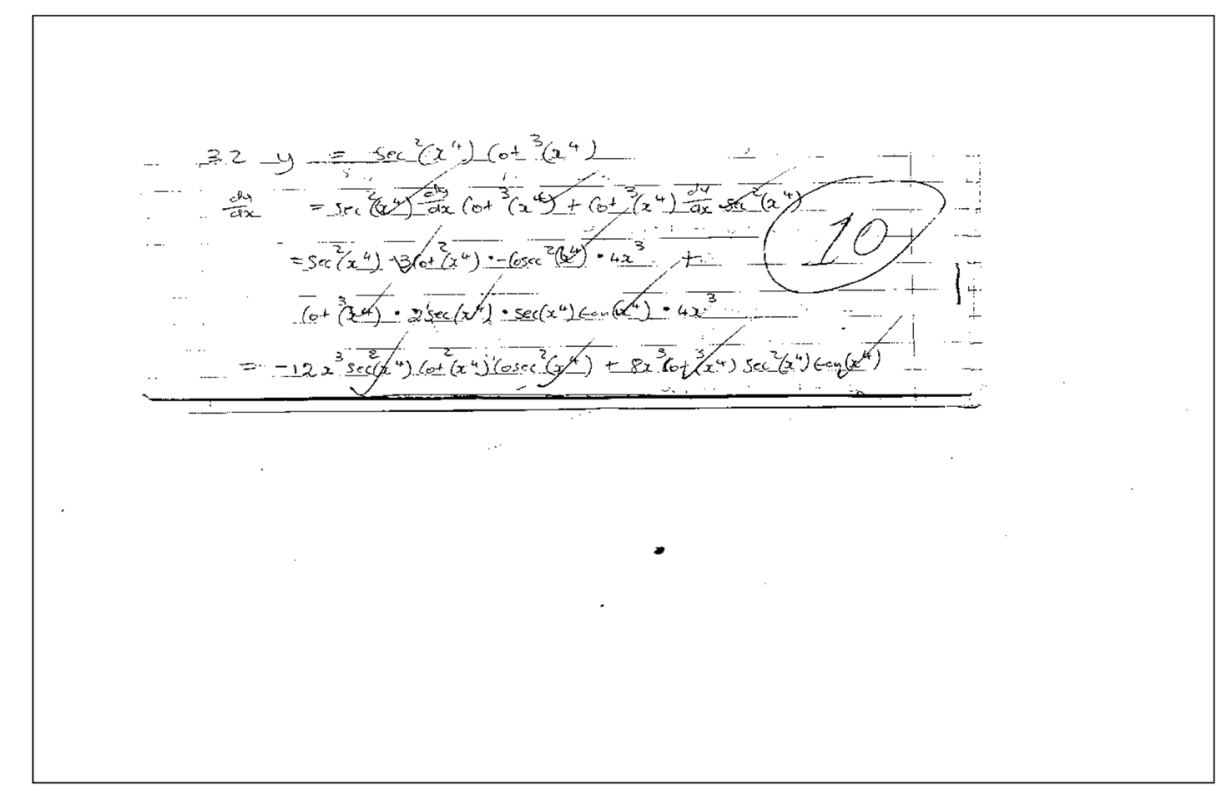

Fig. 5 Error in simplification of trigonometric functions 


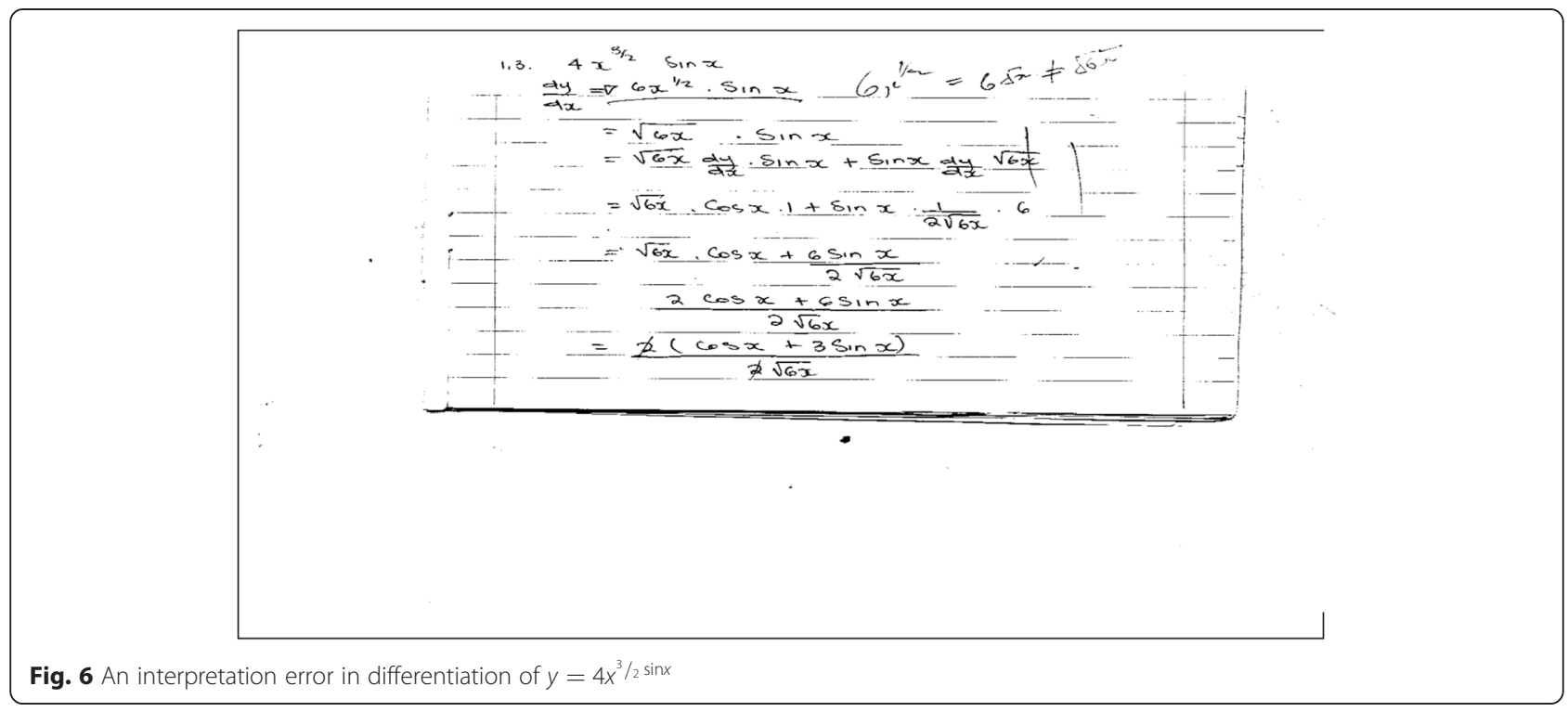

error originates from an over-generalisation of the differentiation of the composite function of trigonometric functions which does not apply in algebraic terms. For example, to differentiate $y=\sin x^{2}$, we have to find the derivative of a sine function first as a cosine function then we find the derivative of $x^{2}$ to get $\frac{d y}{d x}=\cos 2 x$. Alternatively, this might be evidence of a lack of a well-developed composite function schema. The same student also wrote that the derivative of $y=\sec ^{2} x^{4}$ is $\frac{d y}{d x}=\tan \left(x^{4}\right) 4 x^{3}$. This originates from the fact that the derivative of $y=\tan x$ is $\frac{d y}{d x}=\sec ^{2} x$ and from an over-generalisation of the symmetric property of equality: if $a=b$, then $b=a$. This can be interpreted differently; the error might originate if $f(x)=\tan x$ then $f^{\prime}(x)=\frac{d}{d x}\left(\sec ^{2} x\right)$. One student failed to apply the sum and the chain rule to differentiate $y=\sin 7 x+\ln 5 x$; instead, he applied the product rule. This student is not yet at a schema level of APOS Theory regarding application of the sum and chain rule in differentiation of trigonometric functions. Four students differentiated $y=\tan ^{3} \sqrt{\cot 7 x}$ as a product of two functions. As a result, they applied the product rule instead of the chain rule. Their attempts show that they are at a pre-action stage regarding the differentiation of a composite function.

\section{Procedural errors displayed by students in task 2}

One student displayed cancellation errors. She did not write one which was the outcome of cancellation. In the last step, she wrote $\tan x \cdot \cot x$ as $\frac{\sin x}{\cos x} \cdot \frac{\cos x}{\sin x}$ and cancelled, which was correct, but she did not write 1 $\sec ^{2} x$; she only wrote $-\sec ^{2} x$ as shown in Fig. 7. This error shows that this student is not familiar with simplification of trigonometric functions. This might be poor understanding of the properties of the number 1 . The fact that she writes correct identities of trigonometric functions indicates she is at the process stage of APOS Theory regarding the simplification of trigonometric functions. The following figure shows an example of the student who demonstrated a procedural error in the differentiation of $y=3 x^{4}-\tan x \csc x$.

Nine students did not change a plus sign when multiplied by a minus sign. This might be carelessness. Alternatively, the error might a lack of algebraic skills from secondary school level. One student made the error of differentiating $y=3 x^{4}$ as $\frac{d y}{d x}=12 x$ instead of $\frac{d y}{d x}=12 x^{3}$. This student apparently knew that he had to apply the power rule but did so incorrectly. This might have been carelessness. Alternatively, it might indicate poor understanding of the power rule. This student might be placed at an action stage of the APOS Theory regarding the power rule schema. Two students wrote that the derivative of $y=\csc x$ is $\frac{d y}{d x}=\csc x \cot x$ instead of $\frac{d y}{d x}=-\csc x$ $\cot x$. This might be a careless mistake. Alternatively, it might indicate poor understanding of derivatives of trigonometric functions. The same two students also did not use brackets to enable them to multiply by a minus sign. This might be aligned with poor algebraic skills.

Three students simplified $4 x^{3 / 2} \sin x$ incorrectly. They took out $2 \sqrt{x}$ as the highest common factor, which is unnecessary. They tried to simplify it further, but they did not remove the highest common factor. They removed 2 as a common factor, which was not the highest common factor. Most students demonstrated poor ability in the simplification of trigonometric functions and in algebraic expressions. Most of the time in mathematical problems, 


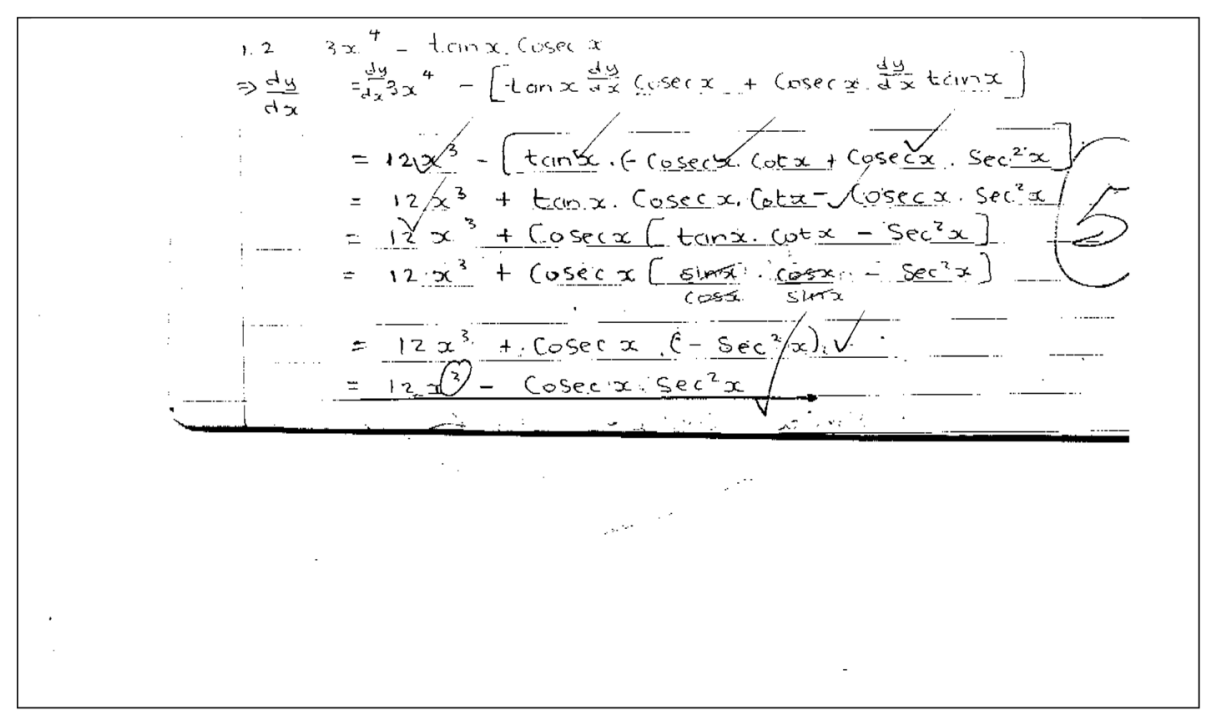

Fig. 7 Procedural error in differentiation of $y=3 x^{4}-\tan x \csc x$

there is a requirement that answers should be left in their simplest form. Thus, to reach closure in any calculation, simplification is a basic requirement

Six students indicated that they did not understand the subtraction of fractions. Their solutions indicated that they applied the power rule to obtain 6 but failed to obtain the correct answer in subtraction of 1 from $\frac{3}{2}$ to obtain $\frac{1}{2}$. One student failed to manipulate the multiplication of $0 \cdot \cos x$ correctly. Instead of obtaining 0 as an answer, she obtained 1 . This might be a poor understanding of the property of zero that any number multiplied by zero is equal to zero. Alternatively, it might be carelessness. One student in the differentiation of $y=\sec ^{2} x^{4} \cot ^{3} x^{4}$ failed to add like terms in simplification. Instead, she tried to remove the highest common factor. The fact that these students achieved correct differentiation indicates that they were at an object stage of APOS Theory. Three students wrote that the derivative of $y=x^{4}$ is $\frac{d y}{d x}=4 x$. This error demonstrates a partial understanding of the power rule. These students might be placed at an action stage regarding the application of the power rule. Eight students failed to apply the power rule to differentiate $y=\cot ^{3} x^{4}$ to obtain $\frac{d y}{d x}=\left(3 \cot ^{2} x^{4}\right)$ $\left(-\csc ^{2} x^{4}\right)\left(4 x^{3}\right)$..

Sixteen students failed to simplify the differentiation of $y=\sqrt{\sin (7 x)+\ln (5 x)}$ to reach the correct solution. They did not cancel correctly. They also did not apply the lowest common denominator (LCD) to simplify these fractional trigonometric functions and a fractional algebraic term. Their solutions showed that they had multiplied the numerators and left the denominators as they were. They also did not add the fractions correctly. The poor simplification of fractional trigonometric functions indicates that these students were not yet at the schema level of the APOS Theory. This refers to the addition of fractional trigonometric functions. Three students differentiated the radical expression incorrectly. Twelve students showed poor understanding of the multiplication of trigonometric fractions. They also showed a lack of closure in the differentiation of $y=\tan ^{3} \sqrt{\cot 7 x}$ owing to poor simplification of fractional trigonometric functions.

\section{Linear extrapolation errors displayed by students in task 2} One student split $\sqrt{\sin (7 x)+\ln (5 x)}$ into $\sqrt{\sin (7 x)}+$ $\sqrt{\ln (5 x)}$. This error originated from $\sqrt{a \times b}=\sqrt{a} \times$ $\sqrt{b}$, which applies in the multiplication of real numbers that are written in a radical form but does not apply in addition and subtraction of real numbers that are written in a radical form. Table 4 shows errors that were displayed by students in task 2 in the study.

\section{Results with regard to the students' third formative assessment task (task 3)}

Errors displayed by students in task 3 were classified into three categories, namely, conceptual, interpretation and procedural errors, as discussed earlier in 5.1.

\section{Conceptual errors displayed by students in task 3}

Eight students did not know that $\ln e=1$; hence, they applied the product rule to differentiate $\tan ^{2} x \ln e$. They also did not understand the concept of a natural logarithm $(\ln x)$. Hence, they differentiated $\frac{1}{2} \ln$ 
Table 4 Students' errors in task 2

\begin{tabular}{|c|c|c|c|c|c|c|}
\hline \multicolumn{2}{|c|}{$\begin{array}{l}\text { Students' written work } \\
\text { in task } 2\end{array}$} & \multirow{2}{*}{$\begin{array}{l}\text { No. of conceptual errors } \\
6\end{array}$} & \multirow{2}{*}{$\begin{array}{l}\text { No. of interpretation errors } \\
1\end{array}$} & \multirow{2}{*}{$\begin{array}{l}\text { No. of linear extrapolation errors } \\
0\end{array}$} & \multirow{2}{*}{$\begin{array}{l}\text { No. of procedural errors } \\
14\end{array}$} & \multirow{2}{*}{$\begin{array}{l}\text { No errors } \\
1\end{array}$} \\
\hline Question & 1.1 & & & & & \\
\hline & 1.2 & 0 & 6 & 0 & 13 & 7 \\
\hline \multirow[t]{3}{*}{ Question } & 2.1 & 1 & 0 & 0 & 2 & 24 \\
\hline & 2.2 & 1 & 0 & 0 & 0 & 27 \\
\hline & 2.3 & 2 & 0 & 0 & 1 & 25 \\
\hline \multirow[t]{3}{*}{ Question } & 3.1 & 8 & 1 & 0 & 12 & 0 \\
\hline & 3.2 & 0 & 1 & 1 & 16 & 0 \\
\hline & 3.3 & 0 & 4 & 0 & 12 & 12 \\
\hline \multicolumn{2}{|c|}{$\begin{array}{l}\text { Total number } \\
\text { of errors }\end{array}$} & 18 & 13 & 1 & 70 & 96 \\
\hline
\end{tabular}

$\cos x$ as $\frac{1}{2} \ln \cos x \cdot-\sin x+\frac{\frac{1}{2}-\sin x}{\cos x}$. One student did not know that $\sqrt{\cos x}=(\cos x)^{\frac{1}{2}} \neq \cos x^{\frac{1}{2}}$, and she differentiated $\ln \sqrt{\cos x}$ incorrectly. For example, her solution was as follows:

$$
\frac{d}{d x}(\ln \sqrt{\cos x})=\frac{1}{\sqrt{\cos x}} \cdot(-\sin x)
$$

. In this error, the student did not know that the derivative of $\sqrt{\cos x}$ is $\frac{1}{2 \sqrt{\cos x}} \cdot-\sin x=\frac{-\sin x}{2 \sqrt{\cos x}}$. This displays poor understanding of the basics of differentiation. The standard rule to find the derivative of $y=\sqrt{x}$ is $\frac{d y}{d x}=\frac{1}{2 \sqrt{x}}$. This student lacked this basic knowledge. As a result, she might be placed in a process stage of the APOS Theory. One student showed errors in differentiation of trigonometric functions when integrated with logarithmic functions. His solution indicated that he did not distinguish between the power rule and the logarithmic differentiation. He differentiated $\ln x^{3}$ as $3 \ln x^{2}$ instead of $\frac{3}{x}$. He wrote that the derivative of $y=\ln e^{2 x+3}$ is $2 x+3 \ln e$ . 1. One student did not substitute $\frac{-\sin x}{2 \cos x}$ with $\frac{-\tan x}{2}$. This error shows poor understanding of basic trigonometric identities such as $\tan x=\frac{\sin x}{\cos x}$. One student showed insufficient understanding of differentiation of a natural logarithmic function in the chain rule as she differentiated $\ln \sec ^{2} x$ as $\ln \sec ^{2} x \cdot 2 \sec x \cdot \sec x$ $\tan x$. The error here was in understanding of natural logarithmic function as this student missed out $\frac{1}{\sec ^{2} x}$. Instead, she copied the problem as it is before differentiating $\sec ^{2} x$. She also differentiated $-\tan 2 x$ as $\sec ^{2} x(-\tan 2 x)$ instead of $-\sec ^{2} x \cdot 2=-2 \sec ^{2} x$. This student might be placed in an object stage of the APOS Theory. One student differentiated $\ln \sec ^{2} x+\ln e^{-\tan ^{2} x}$ incorrectly as she wrote that $\frac{y^{\prime}}{y}=\frac{1}{\sec ^{2} x} \cdot 2 \sec x \cdot \operatorname{cosec} x \tan x+\left(-\tan ^{2} x\right) \ln e$ is the derivative of $\ln \sec ^{2} x+\ln e^{-\tan ^{2} x}$. This solution indicated that this student did not know that the derivative of $\sec x$ is $\sec x \tan x$. One student wrote $\frac{1}{\sin x}$ as the derivative of $\sec x$. One student wrote $\sec x$ as the derivative of $\tan x$, while another one student differentiated $-\tan ^{2} x$ as $-2 \tan x \cdot-\sec ^{2} x$. The error was to write a minus sign in front of $\sec ^{2} x$. One student showed poor understanding of the chain rule as they differentiated $\tan ^{2} x$ as $-\tan ^{2} x \sec ^{2} x$ instead of $-2 \tan x \sec ^{2} x$. One student wrote that the derivative of $\sec ^{2} x$ is $-\csc ^{2} x$.

One student wrote that the derivative of $-\tan ^{2} x$ is $\tan ^{2} x \cdot 2 \tan x \sec ^{2} x$. Another student wrote that the derivative of $\tan x$ is $\cot x$. Two students wrote that the derivative of $-\tan ^{2} x$ is $\ln \sec x \cdot 0-\sec ^{2} x$. Two students did not know how to differentiate a composite function of a trigonometric function such as $-\tan ^{2} x$. One of these two students wrote $-\sec x$ as the derivative of $-\tan ^{2} x$. The other students wrote $-\left(\sec ^{2} x\right)^{2} \sec ^{2} x$ as the derivative of $-\tan ^{2} x$ and also wrote that the derivative of $\sec ^{2} x$ is $(\sec x \tan x)^{2}$. This error may have originated from the algebraic over-generalisation that if $a=b$, then $a^{2}=b^{2}$.

\section{Interpretation errors displayed by students in task 3}

Fourteen students fused two functions into one function. They treated $x^{3} e^{2 x+3}$ as the first function and $\sqrt{\cos x}$ as the second function. One student did not know the derivative of $y=\sec ^{2} x$; as a result, she wrote that the derivative of $y=\sec ^{2} x$ is $\frac{d y}{d x}=\tan x$. This error originated from over-generalisation of the symmetric property, which states that for any quantities $a$ and $b$, if $a=b$, then $b=a$. This is not the case in derivatives.

One student wrote that the derivative of $y=-\left(\sec ^{2} x\right)^{2}$ $\sec ^{2} x$ is $\frac{d y}{d x}=-\tan ^{2} x$ and also wrote that the derivative of $y=\sec ^{2} x$ is $\frac{d y}{d x}=(\sec x \tan x)^{2}$. This originated from the algebraic over-generalisation such as if $a=b$, then $a^{2}=b^{2}$.

\section{Procedural errors displayed by students in task 3}

One student showed poor understanding of identities as he wrote $\cot \theta=\tan \theta$. As a result, he substituted $\cot \theta$ 
with $\tan \theta$. One student failed to multiply radical trigonometric functions correctly. He manipulated $\frac{1}{\sqrt{\cos x}}$. $\frac{1}{2 \sqrt{\cos x}} \cdot \frac{-\sin x}{1}$ incorrectly. As a result, he obtained $\frac{-\sin x}{\sqrt{\cos x}}$ instead of $\frac{-\sin x}{2 \cos x}$. One student failed to apply the LCD correctly in $y=x^{3} e^{2 x+3} \sqrt{\cos x}$. Two students differentiated $y=2 x+3 \ln e$ incorrectly. They did not apply the sum rule.

They also treated $y=2 x+3 \ln e$ as if it required the application of the product rule, treating $2 x+3$ as the first function and $\ln e$ as the second function. They wrote that the derivative of $(2 x+3) \ln e$ is $2 \ln e$. Table 5 shows errors displayed by students in task 3 .

\section{Discussion}

This section summarises the results and the implications thereof in the learning of derivatives of trigonometric functions. A certain number of students showed that they were at the action stage of the APOS Theory, as they could not manipulate application of the sandwich theorem to prove that $\lim \frac{\sin \phi}{\phi}=1$. In an APOS analysis this is evidence that students enter universities with a limited understanding of limits with regard to the application of trigonometric functions. In secondary school, they only studied limits of algebraic functions. They did not study limits involving trigonometric functions, as they were not included in their curriculum. These results suggest that university lecturers, particularly first year mathematics lecturers, should handle the introduction of other functions such as exponential, logarithmic and trigonometric functions with care. Students should be guided to get an understanding of the basic special trigonometric limits as they hear and/or see them for the first time when learning mathematics.

A small number of students could not write the correct cosine compound angle formulae. These students might be placed at a pre-action stage of the APOS Theory, as the correct cosine compound angle formulae were unknown to them. They could not start the first step of calculation. An APOS analysis showed that these students had studied complicated trigonometric compound angle formulae only in their last year of

\begin{tabular}{|c|c|c|c|c|c|}
\hline \multicolumn{2}{|l|}{$\begin{array}{l}\text { Students' } \\
\text { written } \\
\text { work in } \\
\text { task } 3 \\
\end{array}$} & \multirow{2}{*}{$\begin{array}{l}\text { No. of } \\
\text { conceptual } \\
\text { errors }\end{array}$} & \multirow{2}{*}{$\begin{array}{l}\text { No. of } \\
\text { interpretation } \\
\text { errors } \\
0\end{array}$} & \multirow{2}{*}{$\begin{array}{l}\text { No. of } \\
\text { procedural } \\
\text { errors }\end{array}$} & \multirow{2}{*}{$\begin{array}{l}\text { No } \\
\text { errors } \\
0\end{array}$} \\
\hline Question & 1 & & & & \\
\hline Question & 2 & 13 & 15 & 4 & 4 \\
\hline Question & 3 & 12 & 02 & 0 & 6 \\
\hline \multicolumn{2}{|c|}{ Total number of errors } & 26 & 17 & 5 & 10 \\
\hline
\end{tabular}

secondary school, that is, at matriculation level. These students entered universities or graduated from secondary school not having yet reached the required schema stage of the APOS Theory regarding the cosine compound angle formulae. This suggests that first year mathematics lecturers should use baseline assessment to find out the prior knowledge of students when they enter university. A baseline assessment will assist lecturers to know where to start their revision in trigonometric functions to link secondary school understanding with the required level of university content knowledge.

Some students did not recall that the derivative of $y=$ $\tan x$ is $\frac{d y}{d x}=\sec ^{2} x$. Their errors might be due to their inability to remember or conceptualise. They demonstrated poor understanding of trigonometric identities. These students might be placed at the action stage of the APOS Theory. These findings suggest that teaching should emphasise that understanding of these formulae is the basis of mastering differentiation of trigonometric functions.

A few students did not realise that $\ln e=1$. As a result, they could not access the appropriate rule to apply. Others demonstrated interpretation errors as they demonstrated a poor understanding of multiplication of trigonometric functions. These students might be placed at the action stage of the APOS Theory regarding multiplication of trigonometric functions. This could have originated from the fact that they did not study multiplication of trigonometric functions in their secondary school curriculum. They only studied the use of basic operational signs of trigonometric functions in their first year of university mathematics. This suggests that lecturers should design activities that allow students to explore basic concepts of differentiation. Some students demonstrated confusion with respect to the composite function and other trigonometric functions. This originated from the fact that they had only studied composite functions towards the end of their learning of derivatives. This suggests that lecturers should explain composite functions, clearly distinguishing them from other functions.

The identification of errors in the learning of derivatives of trigonometric functions assists lecturers to know their students' weaknesses and also to find out the origin of the errors displayed. Revision of activities in classroom discussions might be used as a tool to rectify students' errors and also to uproot the origin of the errors identified. Wood (1988) suggests that to avoid the formation of entrenched errors, there should be open class discussions and interactions that focus on addressing students' errors as they arise in a classroom situation. He further explains that students might gain better mathematical understanding when they share their interpretations of mathematical problems in classroom 
discussions. This current study recommends the use of the ACE teaching cycle as a pedagogical approach to enhance students' understanding in their learning of derivatives of trigonometric functions.

\section{Conclusions}

This study investigated errors displayed by students registered for Mathematics in Chemical Engineering. This was done in order to trace causes or origins of the errors displayed to enable the lecturer (researcher) to develop strategies to eliminate the errors in the learning of derivatives of trigonometric functions. Strategies include designing learning activities that may lead students to explore and discuss how they commit these errors. Errors displayed by students in this study mostly originated from their prior learning of mathematics and overgeneralisation of certain mathematical rules. The students' prior learning had been dominated by rote learning of routines or procedures without their having made sense of these. The findings of this study inform lecturers on how they should prepare lessons to guide students to understand and apply restrictions of certain differentiation rules and formulae.

The use of the APOS Theory is a utility, and, as such, it emphasises individual attention to obtain students' explanations, discussions and elicit debates. The use of the APOS Theory is an important supplement as it also provides a sense of how and why students perform to reach their full potential and what form of assistance they require to be in a position to devise viable solutions to their particular mathematical problems. This, without doubt, requires lecturers to make an investment in time and patience if lecturers are seriously concerned about enhancing the understanding and comprehension of students in as far mathematics is concerned, particularly when dealing with students enrolled in an ECP to develop their understanding of derivatives of trigonometric functions.

\section{Abbreviations}

AMESA: Association for Mathematics Education of South Africa; APOS: Action Process Object Schema; ECP: Extended Curriculum Programme.

\section{Competing interests}

The author declares that he has no competing interests.

\section{Authors' contribution}

Dr. Sibawu Witness Siyepu is the sole author of this article, as a result my contribution is hundred percent of the paper. I developed the paper from my doctoral degree thesis as an individual or alone. I conclude by saying I did the whole job. The author is Dr. S.W. Siyepu.

\section{Authors' information}

The author is a senior lecturer in mathematics education at Cape Peninsula University of Technology.

\section{Acknowledgements}

The work reported here was part of a doctoral study of the author done at the University of the Western Cape, in South Africa, under supervision of
Professor Monde Mbekwa and Professor Cyril Julie. The author acknowledges supervisors and Cape Peninsula University of Technology for funding throughout the entire duration of a doctoral study.

Received: 23 March 2015 Accepted: 30 September 2015

Published online: 15 October 2015

\section{References}

Arnon, I, Cottrill, J, Dubinsky, E, Oktaç, A, Fuentes, SR, Trigueros, M, \& Weller, K. (2014). APOS Theory: a framework for research and curriculum development in mathematics education. London: Springer.

Barnes, M. (1995). An intuitive approach to calculus. Retrieved from http:// hsc.csu.edu.au/maths/teacher_resources/2384/barnes.htm.

Brijlall, D, \& Ndlovu, Z. (2013). High school learners' mental construction during solving optimisation problems in Calculus: a South African case study. South African Journal of Education, 33(2), 1-18.

Brodie, K. (2005). Using cognitive and situative-perspectives to understand teacher interaction with learner errors. In HL Chick \& J Vincent (Eds.), Proceedings of the $29^{\text {th }}$ Conference of the International Group for the Psychology of Mathematics Education (pp. 177-184). Melbourne: PME.

Brodie, K. (2006). Teaching mathematics for equity: learner contributions and lesson structure. African Journal for Research in Mathematics, Science and Technology Education, 10(1), 13-24.

Brodie, K. (2010). Teaching mathematical reasoning in secondary school classrooms. London: Springer.

Brodie, K, \& Berger, M. (2010). Toward a discursive framework for learner errors in mathematics. In V Mudaly (Ed.), Proceedings of the eighteenth annual meeting of the Southern African Association for research in mathematics, science and technology education. Improving the quality of Science, Mathematics and Technology Education through relevant research and a continued multi- and inter-disciplinary approach to teaching (pp. 169-181). Durban: University of Kwa-Zulu Natal. 1.

Challenger, M. (2009). From triangles to a concept: a phenomenographic study of A-level students' development of the concept of trigonometry. Unpublished PhD thesis. Coventry: University of Warwick.

Choat, E. (1981). Understanding in young children's mathematics. Mathematics in school, 10(2), 18-21. http://www.jstor.org/stable/pdfplus/30213633.pdf?acceptTC= true. 28 March 2013.

Clark, JM, Gordero, F, Cottrill, J, Czarnocha, B, DeVries, DJ, John, D, Tolias, G, \& Vidakovic, D. (1997). Constructing a schema: the case of the chain rule. Journal of Mathematical Behaviour, 16(4), 345-364.

Davis, RB. (1984). Learning mathematics: the cognitive science approach to mathematics education. London: Groom Helm.

Department of Basic Education (DoBE). (2011). Curriculum and assessment policy statement/ Grades 10-12. Pretoria: Mathematics.

Devetak, I, Glazar, SA, \& Vogrinc, J. (2010). The role of qualitative research in science education. Eurasia Journal of Mathematics, Science and Technology Education, 6(1), 77-84.

Drews, D. (2005). Children's mathematical errors and misconceptions: perspectives on the teacher's role. In A Hansen (Ed.), Children errors in mathematics: Understanding common misconceptions in primary schools ( $\mathrm{pp}$. 14-21). Britain: Paperback.

Dubinsky, E. (1991). Reflective abstraction in advanced mathematical thinking. In D Tall (Ed.), Advanced mathematical thinking (pp. 231-250). Dordrecht: Kluwer.

Dubinsky, E, \& McDonald, MA. (2001). APOS: a constructivist theory of learning in undergraduate mathematics education research. In D Holton (Ed.), The teaching and learning of mathematics at university level, An ICMI Study (pp. 275-28). Netherlands: Kluwer Academic Publishers.

Engelke, N, Oehrtman, M, \& Carleson, M. (2005). Composition of functions: pre-calculus students understandings. In GM Lloyd, M Wilson, JLM Wilkins, \& SL Behm (Eds.), Proceedings of the $27^{\text {th }}$ Annual meeting of the north American Chapter of the International Group for the Psychology of Mathematics education (pp. 25-32). Roanoke: Virginia Tech.

Foster, D. (2007). Making meaning in algebra examining students' understandings and misconceptions. Assessing Mathematical Proficiency, 53, 163-176.

Gray, SS, Loud, BJ, \& Sokolowski, CP. (2009). Calculus students' use and interpretation of variables; algebraic vs. arithmetic thinking. Canadian Journal of Science, Mathematics and Technology Education, 9(2), 59-72. 
Hatano, G. (1996). A conception of knowledge acquisition and its implications for mathematics education. In P Steffe, P Nesher, P Cobb, G Goldin, \& B Greer (Eds.), Theories of mathematical learning (pp. 197-217). New Jersey: Lawrence Erlbaum.

Jojo, Z, Maharaj, A, \& Brijlall, D. (2011). The reliability of a research instrument used to measure mental constructs in the learning of chain rule in calculus. In H Venkat \& AA Essien (Eds.), "Mathematics in a globalised World". In the proceedings of the Seventeenth National Congress of the Association for Mathematics education of South Africa (AMESA) (pp. 336-349). Johannesburg: University of the Witwatersrand.

Jojo, ZMM. (2014). Instructional design in the formation of mental images and the genetic decomposition of a concept. Journal of Educational and Social Research, 4(3), 139-148.

Kiat, SE. (2005). Analysis of students' difficulties in solving integration problem. The Mathematics Educator, 9(1), 39-59.

Luneta, K, \& Makonye, PJ. (2010). Learner errors and misconceptions in elementary analysis: a case study of a grade 12 class in South Africa. Acta Didactica Napocensia, 3(3), 35-46.

Maharaj, A. (2008). Some insights from research for teaching and learning mathematics. South African Journal of Education, 28, 401-414.

Maharaj, A. (2013). An APOS analysis of natural students' understanding of derivatives. South African Journal of Education, 33 (1), Art.\#458,19 pages, http://www.sajournalofeducation.co.za/index.php/saje/article/view/458.

Makgato, M. (2007). Factors associated with poor performance of learners in mathematics and physical science in secondary schools in Soshanguve, South Africa, Africa. Education Review, 4:1, 89-103: http://dx.doi.org/10.1080/ 18146620701412183

Matz, M. (1980). Towards a computational theory of algebraic competence. Journal of Mathematical Behavior, 3(1), 93-166.

Mundy, J. (1984). Analysis of errors of first-semester calculus students. In A Bell, B Low, \& J Kilpatrick (Eds.), Theory research and practice in mathematical education. Working group Reports and Collected papers from the 5 th International Congress on Mathematical Education (pp. 170-172). Nottingham: Shell Centre for Mathematical Education.

Naidoo, K, \& Naidoo, R. (2009). Students using a mathematical learning project work to conceptualise the derivative. International Conference to Review Research in Science, Technology and Mathematics Education. Proceedings of epiSTEME 3 (pp. 180-186). Mumbai: Macmillan Publishers.

Nesher, P. (1987). Towards an instructional theory: the role of student's misconceptions. For Learning of Mathematics, 7(3), 33-40.

Olivier, A. (1989). Handling pupils' misconceptions. http://academic.sun.ac.za/ mathed/MALATI/Misconceptions.htm

Orhun, N. (2010). The gap between real numbers and trigonometric relations. Quaderni di Ricerca in Didattica, 20, 175-184.

Orton, A. (1983a). Students' understanding of differentiation. Educational Studies in Mathematics, 14(3), 235-250.

Orton, A. (1983b). Students' understanding of integration. Educational Studies in Mathematics, 14, 1-18.

Paramenswaran, R. (2007). On understanding the notion of limits and infinitesimal quantities. International Journal of Science and Mathematics Education, 5, 193-216.

Peal, D. (2010). Approaches to teaching with mathematics. Connection, 1(3), 1-12.

Pillay, E. (2008). Grade twelve learners' understanding of the concept of derivative. Unpublished masters' thesis). Durban: University of KwaZulu-Natal.

Ryan, J. (1992). Integrating computers into the teaching of calculus: differentiating student needs. In B Southwell, B Perry, \& K Owens (Eds.), Proceedings of the $13^{\text {th }}$ Annual Conference of the Mathematics Education Research Group of Australasia (pp. 478-487). Richmond: University of Western Sydney. 4-8 July.

Ryan, J, \& Williams, J. (2000). Mathematical discussions with children: exploring methods and misconceptions as a teaching strategy. Manchester: Centre for mathematics education: University of Manchester.

Skane, ME, \& Graeber, AO. (1993). A conceptual change model implemented with college students: distributive law misconceptions. Third International Conference on Misconceptions in Science and Mathematics. NY: Ithaca.

Skemp, RR. (1976). The psychology of learning mathematics (2nd ed.). London: Penguin.

Smith, JP, DiSessa, AA, \& Rosehelle, J. (1993). Misconceptions reconceived: constructivist analysis of knowledge in transition. The Journal of the Learning Science, 3(2), 115-163.
Siyepu, SW. (2010). Socio-cultural approaches involved when university students find derivatives. In MD De Villiers (Ed.), Proceedings of the sixteenth annual congress of the Association for Mathematics Education of South Africa (AMESA). "Mathematics: The pulse of the nation". Durban: KwaZulu-Natal University.

Siyepu, SW. (2013a). Students' interpretations in learning derivatives in a university mathematics classroom. In Z Davis \& S Jaffer (Eds.), Proceedings of the 19th Annual Congress of the Association for Mathematics Education of South Africa (pp. 183-193). Cape Town: AMESA.

Siyepu, SW. (2013b). An exploration of students' errors in derivatives in a university of technology. Journal of Mathematical Behavior, 32(3), 577-592.

Siyepu, SW, \& Ralarala, MK. (2014). Making sense of mathematical discourse: implications for success in the learning of differentiation in a university classroom. Alternation, 12, 326-357.

Swan, M. (2001). Dealing with misconceptions in mathematics. In P Gates (Ed.), Issues in Teaching Mathematics. London: Falmer Press.

Tall, D. (1993). Students' difficulties in calculus. Proceedings of working group 3 on students' difficulties in calculus, ICME-7 Quebec, Canada: 13-28. http:// homepages.warwick.ac.uk/staff/David.Tall/downloads.html.

Tall, D, \& Vinner, S. (1981). Concept image and concept definition in mathematics with particular reference to limits and continuity. Educational Studies in Mathematics, 12, 151-169.

Tarmizi, R. A. (2010). Visualising students' difficulties in learning calculus. Proceedings of the International Conference on Mathematics Education Research (pp 377-383), Universiti Putra Malaysia: 377-383. http:// www.sciencedirect.com/science/article/pii/S1877042810021580

Thompson, PW, Byerley, B, \& Hatfield, N. (2013). A conceptual approach to calculus made possible by technology. Computers in the schools, 30, 124-147.

Ubuz, B. (2001). First year engineering students' understanding of tangency, numerical calculation of gradients and the approximate value of a function at a point through computer. Journal of Computers in Mathematics and Science Teaching, 20(1), 111-135.

Uygur, T. \& Ozdas, U. (2005). Misconceptions and difficulties with the chain rule. The Mathematics Education into the 21st Century Project Universiti Teknologi Malaysia. Reform, Revolution and Paradigm Shifts in Mathematics Education Johor Bahru, Malaysia, Nov 25th - Dec 1st 2005 http:// math.unipa.it/ grim/21_project/21_malasya_Uygur209-213_05.pdf

Wangberg, A., Engelke, N., \& Karakok, G, (2010). Functions composition and the chain rule in calculus. http://sigmaa.maa.org/rume/crume2011/RUME2011_ FinalSchedule_files/PreliminaryReportsShortPapers/wangberg_proceedings.pdf

Weber, K. (2008). Teaching trigonometry functions: lessons learned from research. Mathematics teacher, 102(2), 144-150.

Wood, D. (1988). How children think and learn. Oxford: Blackwell.

Zandieh, M. (1997a). What is the role of the definition in a student's understanding of the concept of derivative? Research Conference in Collegiate Mathematics Education. Mount Pleasant: Central Michigan University.

Zandieh, M. (1997b). The evolution of student understanding of the concept of derivative. (Unpublished doctoral dissertation). Corvallis: Oregon State University.

Zandieh, M. (2000). A theoretical framework for analysing student understanding of theconcept of derivative. In E. Dubinsky, A.H. Schoenfeld, \& J. Kaput (eds.), Research in Collegiate Mathematics Education IV. Providence, American Mathematical Society: 103-127 